\title{
AVALIAÇÃO DE SISTEMA DE TRATAMENTO DE CARCAÇAS DE FRANGOS PELO MÉTODO DA COMPOSTEIRA-WINDROW
}

\author{
EVALUATION SYSTEM FOR TREATMENT OF POULTRY CARCASSES BY BIN \\ COMPOST-WINDROW METHOD
}

\author{
Ed Carlo Rosa Paiva ${ }^{1}$, Antônio Teixeira de Matos ${ }^{2}$, Antover Panazzolo Sarmento ${ }^{3}$, Heber \\ Martins de Paula ${ }^{4}$, Eliane Aparecida Justino ${ }^{5}$
}

Recebido em 15 de dezembro de 2011; recebido para revisão em 15 de dezembro de 2011; aceito em 27 de dezembro de 2011; disponível on-line em 09 de janeiro de 2012.

\section{PALAVRAS CHAVES: \\ Carcaça de frango; \\ Compostagem; \\ Composteira;}

\section{KEYWORDS:}

Poultry carcasses;

Composting;

Bin method;
RESUMO: O presente trabalho buscou avaliar a eficiência do processo de compostagem por composteira para tratamento da carcaça de frango quanto à estabilização da matéria orgânica e a eliminação de microrganismos patogênicos, dando ênfase ao procedimento adotado pelos criadores da Zona da Mata Norte de Minas Gerais. Os materiais utilizados no experimento foram cama de frango, palha de café e carcaça de frango. A montagem foi feita em camadas e, em proporções recomendadas pela literatura, sendo a adição de água correspondente a $20 \%$ da massa de carcaças de frango. Os parâmetros monitorados durante o processo, foram temperatura, relação $\mathrm{C} / \mathrm{N}$, sólidos voláteis $(\mathrm{SV}), \mathrm{pH}$, capacidade de troca catiônica (CTC) e conteúdo de água. Para avaliação da eficiência do processo foi avaliada a redução de SV e o índice $\mathrm{CTC} / \mathrm{COT} \geq 1,7$ (grau de estabilização da matéria orgânica) e eliminação de Salmonella e redução de coliformes termotolerantes (higienização do composto). Após 90 dias, os resultados se mostraram satisfatórios, tanto em termos de estabilização da matéria orgânica, quanto da higienização do composto, que é a eliminação de Salmonella e a redução de coniformes termotolerantes a níveis satisfatórios. A redução de SV e o índice CTC/COT foram, respectivamente, 22,05\% e $5,75 \%$. De acordo com estes resultados concluiu-se que o processo se mostrou satisfatório no tratamento de carcaças de frango.

ABSTRACT: The aim of this work was evaluate the composting process by bin method for the treatment of poultry carcasses where as organic matter stabilization and pathogenic microorganism elimination, emphasizing the procedure adopted by poultry farmers of Zona da Mata Norte of Minas Gerais. The materials used in the experiment were coffee straw, poultry litter and poultry carcasses. The building was in layers, in proportion recommended by bibliography and it was added water corresponding the $20 \%$ of carcasses mass. The parameters monitored during the process were: temperature, $\mathrm{C} / \mathrm{N}$ ratio, volatiles solids (VS), $\mathrm{pH}$, cation-exchange capacity (CEC) and water content. For assessment of the efficiency of each process the reduction of VS and CEC/TOC index, which CEC/TOC $\geq 1,7$ (stabilization grade of organic matter); the Salmonella elimination and thermotolerants coliforms reduction (sanitization of compost) were evaluated. After 90 days, the results were satisfactory, not only in the organic matter stabilization, but also in the compost sanitization, which is the absence of Salmonella and satisfactory reduction of thermotolerants coliforms. The reduction of VS and the CEC/TOC index were, respectively $22,05 \%$ and 5,75 . According the results, it was concluded that the process showed satisfactory in the treatment of poultry carcasses. 
* Contato com os autores:

${ }^{1}$ e-mail : edcarlopaiva@yahoo.com.br (E. C. R. Paiva)

Professor do Departamento de Engenharia Civil da Universidade Federal de Goiás, unidade Catalão - GO.

2e-mail : atmatos@ufv.br (A. T. Matos)

Professor do Departamento de Engenharia Agrícola da Universidade Federal de Viçosa, Viçosa - MG.

33e-mail : antoverps@hotmail.com (A. P. Sarmento)

Professor do Departamento de Engenharia Civil da Universidade Federal de Goiás, unidade Catalão - GO.

${ }^{4}$ e-mail : heberdepaula@hotmail.com (H. M. Paula)

Professor do Departamento de Engenharia Civil da Universidade Federal de Goiás, unidade Catalão - GO.

${ }^{5}$ e-mail : eliane_civ@hotmail.com (E. A. Justino)

Professora do Departamento de Engenharia Civil da Universidade Federal de Goiás, unidade Catalão - GO.

\section{INTRODUÇÃO}

O grande crescimento populacional presenciado em nosso planeta tem gerado uma proporcional demanda por alimentos, materiais e insumos. Entretanto, para suprir essa demanda, tem sido gerada grande quantidade de resíduos, subprodutos da atividade humana constituindo grande problema de ordem social, econômica e ambiental. Dentre as atividades produtoras de alimentos, encontra-se a produção de frangos de corte, geradora de grande quantidade de resíduos. Nessa atividade, o Brasil é hoje um dos maiores produtores e o maior exportador de carne de frango do mundo e crescem a cada ano e, juntamente com ela, aumenta também a quantidade de resíduos gerados.

Segundo a AVIZOM (2006) Associação dos Avicultores que atua na Zona da Mata, cada ave produz cerca de $1,4 \mathrm{~kg}$ de excretas, o que daria, aproximadamente, 12,4 milhões de toneladas de excretas produzidas no Brasil, nos últimos dois anos. A mesma associação afirma que, além da "cama de frango" (excretas mais material palhoso usado na cobertura dos pisos dos criatórios) descartada, 5 a 15\% das aves morrem de causas naturais durante a criação, e, segundo dados da mesma associação, estima-se que no mesmo período, foram mortas, em média, 900 milhões de aves. Na região de atuação da AVIZOM (Zona da Mata Norte de Minas Gerais), a associação informou que são abatidas, diariamente, cerca de 180.000 aves, significando uma produção diária de 252 toneladas de dejetos e 18 mil aves mortas, correspondendo uma produção anual de 75.600 toneladas de excretas e cerca de 6,48 milhões de aves mortas.

A cama de frango descartada dos criatórios, antes Instrução Normativa (IN) $n^{\circ} 8$, do Ministério da Agricultura, Pecuária e Abastecimento, não constituía problema ambiental, sendo, ao contrário, responsável pela viabilidade econômica do sistema de integração de frango na região, uma vez que todo esse material era comercializado como suplemento alimentar de gado. Com a promulgação da $\mathrm{IN} \mathrm{n}^{\circ} 8$, em março de 2004, proibindo a prática de alimentar outros animais com a cama de frango, além de leis ambientais, tanto estaduais quanto federais, exigem dos avicultores maior cuidado no manejo desse resíduos, bem como da disposição final das carcaças de aves, de forma a atender a legislação vigente, seja por questões sanitárias ou mesmo ambiental proíbe o seu lançamento em cursos d'água, enterro sem critério ou uso na alimentação animal.

Nesse sentido, tornou-se urgente o desenvolvimento de tecnologias que possibilite a destinação adequada, sob o ponto de vista sanitário e ambiental, se possível, com o aproveitamento desse resíduo para fins agrícolas. Para que isso seja possível, deve-se, no entanto, conhecer melhor os componentes químicos e microbiológicos desses resíduos, de forma a se obter um adubo orgânico sanitariamente seguro e que agregue valor econômico.

O método de compostagem de carcaças de animais em composteira é uma alternativa de fácil implantação e requer pouco investimento de implantação e operação, mas requer cuidados com a qualidade sanitária do processo.

A compostagem de carcaças de animais é o processo pelo qual se colocam as carcaças em camadas entre materiais palhosos e esterco permitindo sua decomposição natural e a redução de sua massa (EPA, 1999).

A compostagem de animais mortos é relativamente nova, se comparada a compostagem de resíduos orgânicos convencionais, tais como os resíduos sólidos

urbanos e resíduos agrícolas. Ela surgiu na cadeia de produção de carne de aves na década de 80 , após uma pesquisa na Universidade de Maryland ter demonstrado que as carcaças de aves eram totalmente biodegradadas em apenas 30 dias. Esse tipo de compostagem surgiu como alternativa às práticas mais comuns de disposição final desses resíduos, que são a queima, o enterro ou alimentação de animais, por ser uma alternativa segura do ponto de vista sanitário e ambiental, sendo de baixo custo de instalação e operação (GRAVES et al., 2000). Essa técnica tem sido mais usada para compostagem de carcaças de frango de corte, mas pode ser usada para carcaça de animais maiores, tais como suínos, perus, bois, cavalos, entre outros. No caso animais de grande porte, recomendase fatiá-los antes de sua disposição nas leiras de compostagem.

A compostagem de animais mortos se diferencia da compostagem de resíduos orgânicos convencionais por apresentar mais de um estágio de degradação ativa. Os materiais que compõe a mistura e que são fontes de carbono e nitrogênio, inicialmente, não se encontram intimamente misturados. Além disso, o processo apresenta um pequeno período de degradação anaeróbia. Segundo relatado por Mukhtar et al.(2004) o processo se desenvolve em dois 
estádios. No inicio do primeiro estádio, no entorno das carcaças, o processo de degradação é anaeróbio, os líquidos e gases formados, se movem em direção a zona aeróbia, formada pelo material de co-compostagem que está no entorno das carcaças, então, os gases e líquidos são capturados pelos microrganismos presentes nessa massa de material e convertidos a dióxido de carbono e água. O material do entorno das carcaças é fonte de carbono e de bactérias, além de funcionarem como um filtro biológico (biofiltro) para o sistema. De acordo com esse conceito, acredita-se que as carcaças de animais funcionam como fontes de nitrogênio orgânico, o material do entorno são a fonte de carbono e a partir da atividade dos microrganismos se tem como produto final, um material estável e relativamente homogêneo, composto por biomassa bacteriana e ácidos húmicos, que pode ser usado para melhoramento (fertilização e condicionamento) do solo.

Segundo Mukhtar et al. (2004), alguns autores acreditam que, em termos de aplicação no solo, os produtos finais da compostagem de animais mortos são comparáveis aos da compostagem de resíduos orgânicos convencionais como resíduos sólidos urbanos e agrícolas e lodo de esgoto. Torna-se importante ressaltar que a compostagem de carcaças, mais especificamente pelo método da composteira, é aplicável para animais com morte natural, não sendo indicada para mortalidade catastrófica resultante de calor excessivo, problemas com instalações, perdas por doença, entre outras. (PEDROSODE-PAIVA, 2004). Entretanto, segundo relatado pela USEPA (2006), a compostagem é boa alternativa para o combate a epidemias de gripe aviária, podendo ser executada no campo ou em galpões. Nesse relatório está descrito que um vírus de alta patogenicidade, como o H5N2, pode ser inativado em três horas, sob temperatura de $55{ }^{\circ} \mathrm{C}$, ou em meia hora, a $60{ }^{\circ} \mathrm{C}$, sendo que essas temperaturas estão dentro da faixa em que o processo de compostagem ocorre.

Objetivou-se com este trabalho avaliar a eficiência do processo de compostagem pelo método combinado composteira-windrow, quanto à estabilização da matéria orgânica e a eliminação de microrganismos patogênicos, para tratamento da carcaça de frango.

\section{MATERIAIS E MÉTODOS}

Neste experimento foi utilizado como materiais estruturantes e fontes de carbono, palha de café e a cama de frango. A escolha desses materiais foi em função de sua grande disponibilidade na Zona da Mata de Minas Gerais, região onde foi conduzida a pesquisa. As proporções dos materiais utilizados na montagem da composteira, seguiram as recomendações de Pedroso de Paiva (2004) e Henry (2003), tendo sido utilizados 0,3 kg de palha de café palha de café para cada $1 \mathrm{~kg}$ de carcaça de frango e $2 \mathrm{~kg}$ de cama-de-frango.

A composteira foi construída com $1,5 \mathrm{~m}$ de comprimento por 1,5 $\mathrm{m}$ de largura e 2,10 $\mathrm{m}$ de altura foi preenchida com 3 camadas de carcaças de frango distribuídas da seguinte forma: 1a camada com $28 \mathrm{~kg}$ de carcaça; 2a camada com $28 \mathrm{~kg}$ de carcaça e $3^{a}$ camada com $27 \mathrm{~kg}$ de carcaça, totalizando $83 \mathrm{~kg}$ de carcaça.

Na Figura 1 está apresentado o esquema de montagem da composteira.

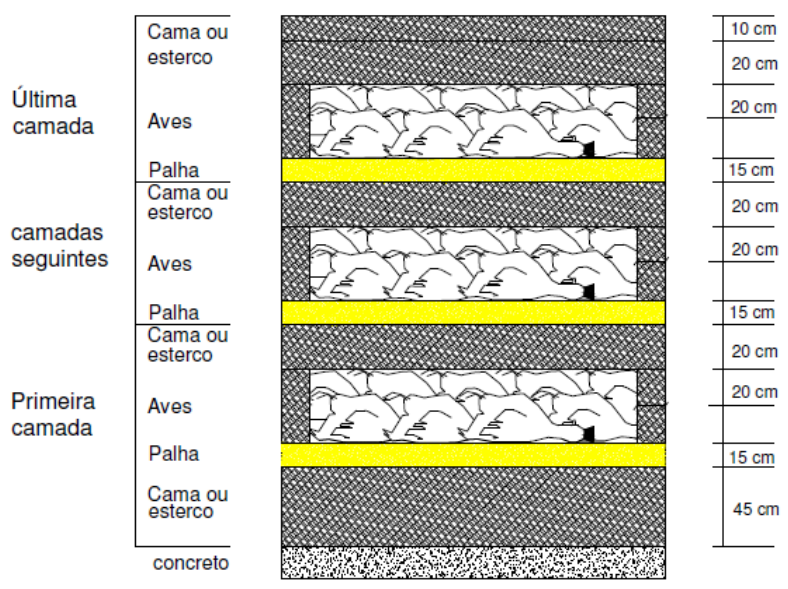

Figura 1: Esquema de montagem das camadas na composteira.

O monitoramento do experimento foi realizado por meio de leituras diárias de temperaturas na base centro e topo da pilha (composteira) e leira (Windrow), além de análises físicas, físico-químicas, químicas e bacteriológicas. Todas as análises foram feitas a cada 20 dias (1을 estágio ou composteira) e a cada 30 dias (2은 estágio ou Windrow). As variáveis analisadas foram carbono facilmente oxidável (CFO), nitrogênio (N), relação carbono por nitrogênio $(\mathrm{CFO} / \mathrm{N})$, sólidos voláteis (SV), a capacidade de troca catiônica (CTC), carbono orgânico total (COT), relação de capacidade de troca catiônica por carbono orgânico total (CTC/COT), análises bacteriológicas Salmonella e coliformes termotolerantes (CTT).

A concentração de sólidos voláteis foi obtida após queima do material em mufla, sob temperatura de 550 으, por 2 horas (KIEHL, 1985 e APHA et al., 1995). O carbono facilmente oxidável foi determinado utilizando-se o método Walkley-Black adaptado (MATOS, 2006). Para a determinação do $\mathrm{Nt}_{\text {otal, foi }}$ utilizado o método de Kjedahl (KIEHL, 1985; APHA et al., 1995), modificado com a adição de ácido salicílico, a fim de proporcionar a redução do nitrato e, assim, sua inclusão na concentração do $\mathrm{N}_{\text {total }}$. As análises bacteriológicas de Salmonella e coliformes termotolerantes (CTT) foram realizadas de acordo com a Instrução Normativa no 62 (MAPA, 2003).

Como indicadores para considerar o fim da compostagem, utilizou-se a estabilização da matéria orgânica (redução de sólidos voláteis e relação $C / N$ ) e sanitização (redução de microrganismos, Salmonella e CTT) em quantidades inferiores a $10^{3}$, com base no Número Mais Provável (NMP) por grama de Sólidos 
Totais (ST).

\section{RESULTADO E DISCUSSÃO}

Na Figura 2 está apresentado o comportamento da temperatura em função do tempo de compostagem.

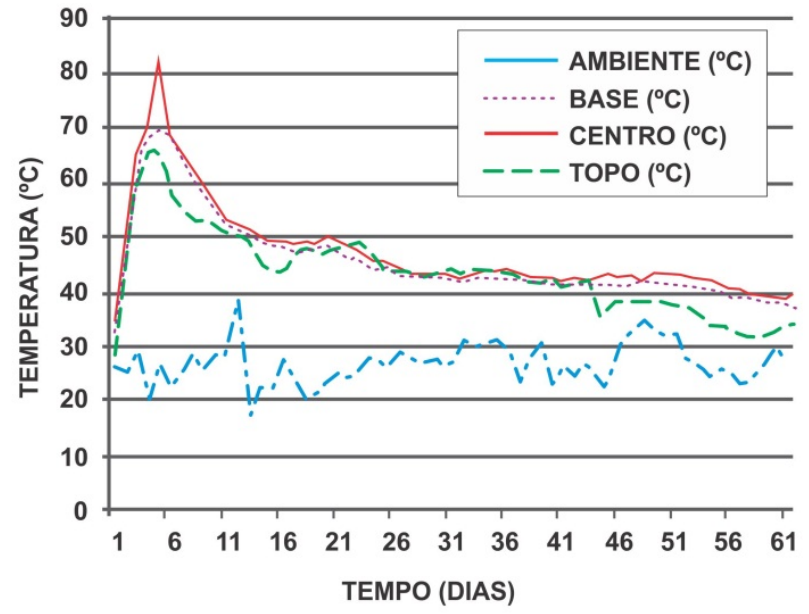

Figura 2: Variação na temperatura do material em função do tempo de compostagem no primeiro estágio ou composteira.

Como pode ser observado na Figura 2 a temperatura do material aumentou, gradativamente, na fase inicial do processo, atingindo $60 \stackrel{\circ}{\mathrm{C}}$, no segundo dia após o fechamento da composteira, atingindo o pico de 82 으, no centro da pilha no 4 으 dia e se manteve acima de $55 \stackrel{\circ}{ } \mathrm{C}$, em todos os pontos monitorados, por quatro dias. Acredita-se que a elevação inicial da temperatura ocorreu devido às condições favoráveis (conteúdo de água adequado e grande disponibilidade de substratos de fácil degradação) para a ação dos microrganismos. A partir do 4ㅇ dia, quando a temperatura atingiu o seu pico nos três pontos monitorados, ela foi decrescendo gradativamente, porém de forma diferenciada, até atingir a temperatura próxima da ambiente. A temperatura do topo pode ter sido afetada pela proximidade com a atmosfera e, portanto, com a temperatura ambiente, o que favoreceu um gradiente de temperatura no sentido de dentro para fora e o fato de estar esta camada de material mais sujeita à perda de água. As temperaturas no interior da massa (centro e base) tiveram decréscimo menos acentuado, provavelmente devido às condições isolantes do material associadas à distância destes pontos em relação à superfície da massa, que possui temperatura ambiente.

Ao final dos 60 dias, fim do 1으 estágio (composteira), observou-se que a temperatura da massa, nas três profundidades monitoradas, se manteve praticamente, uniforme. Observou-se tendência da temperatura da massa do material da composteira entrar em equilíbrio com a temperatura ambiente. A temperatura máxima citada pela literatura para esse processo é, em torno, de 71 oC (HENRY, 2003, MUKHTAR et al. 2004), podendo alcançar 76 C (PEDROSO-DE-PAIVA, 2004). Kube (2002) relatou que, em compostos nos quais a temperatura ficou acima de $65 \stackrel{\circ}{\circ}$, a atividade microbiana foi diminuída e acima de 71 oc foi interrompida. Esse fato pode explicar a queda brusca na temperatura, após ser atingido o pico de 82 o C. Costa et al. (2006), avaliando quatro sistemas de compostagem, observou temperaturas máximas em torno de $60 \stackrel{\circ}{ } \mathrm{C}$, no primeiro estágio.

A temperatura do material mantido na composteira, em todos os pontos monitorados, ficou acima de 55 o $C$ por apenas quatro dias, enquanto que Mukhtar et al. (2004) relataram que a maioria dos pesquisadores acredita que essa temperatura deva permanecer na faixa de 55 ㅇ $\mathrm{C}$ a 60 으, em todo composto, por uma a duas semanas. A permanência da temperatura nessa faixa, por tão pouco tempo, pode ser devido ao baixo conteúdo de água do material, durante o processo, uma vez que, procurando-se repetir os mesmos procedimentos recomendados aos avicultores, pela agroindústria da região, não houve verificação se o conteúdo inicial de água encontrava-se dentro da faixa recomendada pela literatura, que varia entre 40 e $60 \mathrm{dag} \mathrm{kg}^{-1}$ (HENRY, 2003, MUKHTAR et al., 2004, PEDROSO-DE-PAIVA, 2004). Entretanto, para eliminação adequada de patógenos, a literatura consultada recomenda que a temperatura do centro da pilha deva alcançar e se manter em torno de 65 oc por um período três dias apenas (KEENER \& ELWELL, 2003, MUKHTAR et al., 2004).

O fato de a temperatura no centro ter permanecido superior a 65 으 por cinco dias (Figura 2) pode ter contribuído para uma adequada eliminação dos patógenos monitorados no 1으 estágio de degradação.

Na Figura 3 está apresentado o comportamento da temperatura no segundo estágio (Windrow).

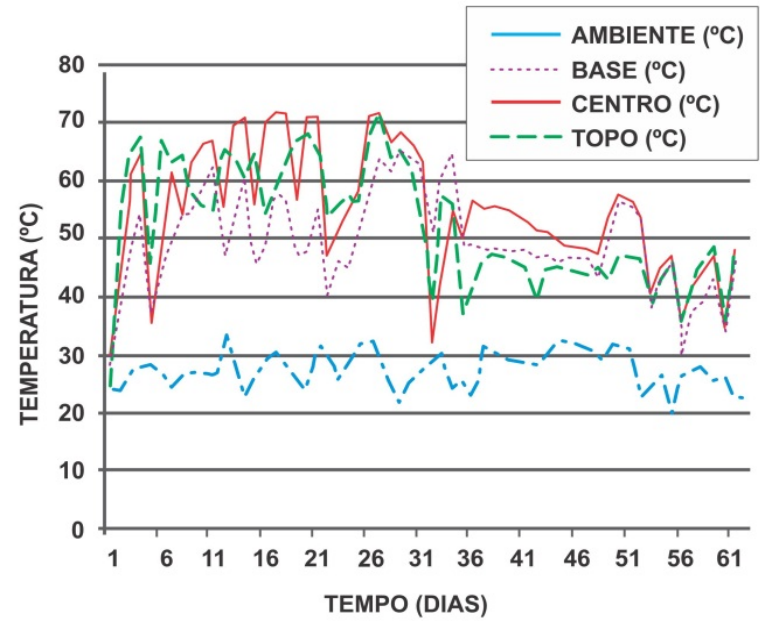

Figura 3: Variação na temperatura do material em função do tempo de compostagem no segundo estágio ou Windrow.

Como pode ser observado na Figura 3 a temperatura no segundo estágio (Windrow) alcançou picos de 71 oC. Costa et al. (2005; 2006) obtiveram temperaturas máximas de, aproximadamente, 66 으 no segundo estágio de compostagem. A diferença nas temperaturas observadas neste trabalho em relação a 
esses autores pode ter várias explicações, dentre as quais, cita-se a manutenção do conteúdo de água na faixa adequada por um maior período de tempo, a relação $\mathrm{C} / \mathrm{N}$ e a degradabilidade dos materiais em compostagem.

O novo aumento na temperatura do material observado no 2 o estágio de compostagem indica que fatores ambientais (notadamente o conteúdo de água e a oxigenação) estariam condicionando o processo de degradação do material dentro da composteira. A remoção do material da composteira, a adição de água e o reviramento periódico permitiram que substratos de fácil degradabilidade fossem transformados com geração de energia, retomando-se, de certa forma, a fase termofílica.

Se no 1 o estágio de degradação o período de altas temperaturas no material pode ser considerado curto, as altas temperaturas alcançadas pelo material no 2 o estágio podem ter complementado o período necessário de altas temperaturas, indispensável para que se alcançasse a eliminação dos patógenos presentes no material.

Na Tabela 1 estão apresentados os resultados das análises físicas; físico-químicas, químicas.

\begin{tabular}{|c|c|c|c|c|c|c|c|}
\hline \multirow{2}{*}{ Dias } & \multirow{2}{*}{$C / N$} & CFO & $\mathbf{N}$ & SV & \multirow{2}{*}{$\frac{\text { CTC }}{\text { cmolc.kg }^{-1}}$} & \multirow{2}{*}{$\frac{\text { COT }}{\text { dag } \mathrm{kg}^{-1}}$} & \multirow[t]{2}{*}{$\mathrm{CTC} / \mathrm{C}$} \\
\hline & & \multicolumn{3}{|c|}{ dag $\mathrm{kg}^{-1}$} & & & \\
\hline 0 & $19.16^{\mathrm{a}}$ & 69.03 & 3.60 & 82.72 & - & 45.96 & - \\
\hline 20 & $9.6^{b}$ & 28.41 & 2.95 & 81.86 & - & 45.48 & - \\
\hline 40 & $13.3^{b}$ & 29.90 & 2.33 & 83.78 & - & 46.54 & - \\
\hline 60 & $27.56^{b}$ & 33.07 & 1.2 & 74.73 & 175 & 41.52 & 4.22 \\
\hline 90 & $22.71^{b}$ & 29.26 & 1.3 & 65.46 & 209 & 36.37 & 5.75 \\
\hline
\end{tabular}

a - calculada por balanço de massas;

b-calculada por amostragem.

$\mathrm{Na}$ Figura 4 estão apresentados os comportamentos de algumas variáveis químicas em função do tempo de compostagem, submetidas a regressão.

Como pode ser observado na Tabela 1 e Figura 4-A, a concentração de nitrogênio decresceu linearmente com o tempo, de 3,6 dag kg-1, inicialmente, passando a ser, 60 dias depois (final do 10 estágio), de 1,2 dag $\mathrm{kg}^{-1}$ chegando a 1,3 dag $\mathrm{kg}^{-1}, 90$ dias depois, 30 dias depois de iniciada o processo Windrow (2은 estágio). Sendo essa redução de $66,67 \%$ no 1 을 Estágio e aumento de 8,33\% no 2 o estágio. Esta grande perda de $\mathrm{N}$ está relacionada às altas temperaturas alcançadas no processo e o alto valor de $\mathrm{pH}$, alcançado pelo material da leira, especialmente no 2 o estágio. Kumar et al. (2007), trabalhando com compostagem de carcaças de animais mortos, onde a fonte de carbono era palha de arroz ou feno de sorgo (com 2 experimentos, sendo o 20 com controle de água e sem carcaças) encontrou redução de 18,05, 19,12 e 22,91\%, respectivamente na concentração de N no material. Das et al. (2002), trabalhado com compostagem de resíduos de incubadora, encontrou reduções de 55,2 e 63,2\%. Orrico Jr et al. (2010), em experimento semelhante, obtiveram reduções de $36,4 \%$ (1을 estágio) e de $71,6 \%$ após 120 dias (final do 20 estágio).

Matos et al. (1998), trabalhando com vários resíduos agrícolas, pelo processo "Windrow", nos quais a fonte de $\mathrm{N}$ era águas residuárias de suinocultura, encontrou, não um decréscimo, mas um aumento na concentração de nitrogênio ao longo do tempo. Os autores consideram que esse aumento foi devido à concentração relativa, proporcionada pela remoção de outros constituintes na forma de gases, principalmente, e pela fixação desse nutriente na massa de material em compostagem, por bactérias capazes de efetuarem esse tipo de atividade. Além disso, essa diferença no comportamento pode estar associada à relação $\mathrm{C} / \mathrm{N}$ inicial da mistura que, no caso desses autores foi de cerca de 30:1, enquanto neste experimento foi de, aproximadamente 19,2:1. Acredita-se que a relação $\mathrm{C} / \mathrm{N}$ baixa e, portanto, a concentração de nitrogênio em excesso para o metabolismo microbiano, associada a altas temperaturas e pH básico, acima de 8,5, tenha favorecido o comportamento observado neste e outros experimentos com resíduos similares.

Conforme pode ser observado na Tabela $1 \mathrm{e}$ na Figura 4-B o comportamento do carbono no processo seguiu a mesma tendência apresentada pelo nitrogênio. Matos et al. (1998), trabalhando com diferentes fontes de carbono para compostagem em conjunto com águas residuárias da suinocultura, observaram um comportamento exponencial. O que é mais adequado, considerando que a decomposição da matéria orgânica por meios aeróbios obedece a uma equação de primeira ordem. 


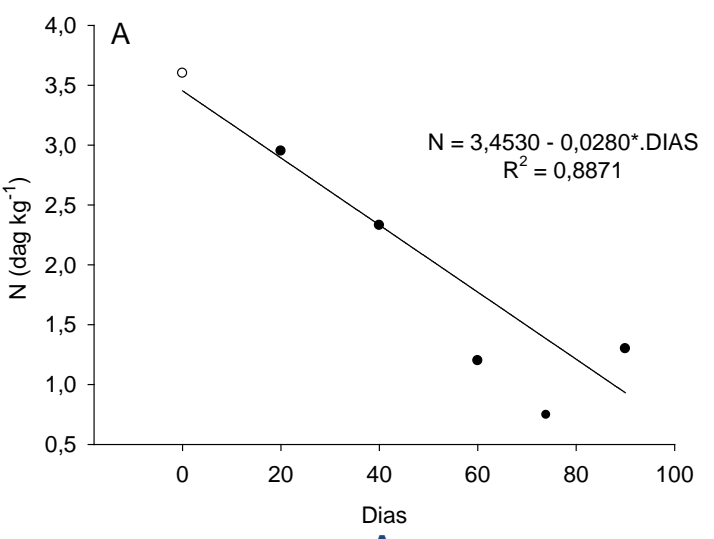

A

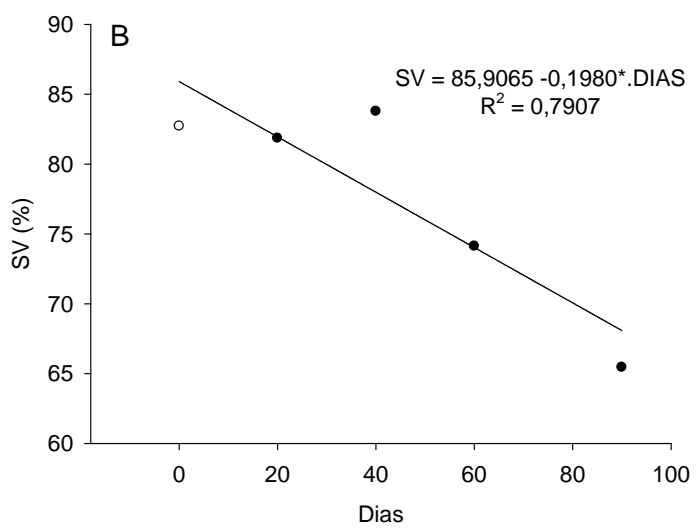

B

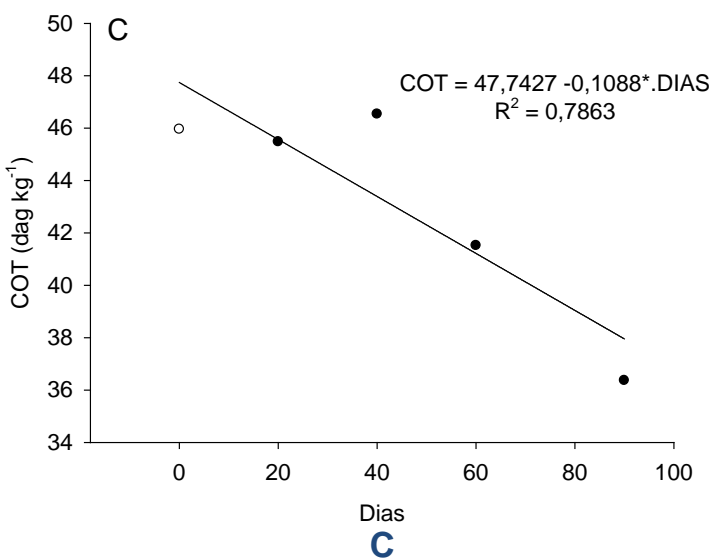

Figura 4: (A) Concentração de Nitrogênio no composto em função do tempo de compostagem. (B) Variação de Sólidos Voláteis em função do tempo de compostagem. (C) Concentração de Carbono Orgânico Total em função do tempo de compostagem. *significativo em nível de $5 \%$ de probabilidade.

A redução na concentração de COT no material, nos primeiros 60 dias de compostagem (1은 estágio), foi muito pequena, sendo mais significativa nos primeiros 30 dias da etapa de reviramento do material ( 2 o estágio). Isto pode ser explicado pelo fato de que, no 10 estágio, como a aeração e o conteúdo de água não foram mantidos em níveis adequados, a degradação se processou de forma muito lenta, tendo ocorrido, basicamente, no entorno das carcaças de frango. Essa afirmação pode ser comprovada avaliandose os dados apresentados na Tabela 1 na coluna de CFO, cujos dados foram obtidos em amostras que foram coletadas na região das carcaças. Porém, como o COT indica a concentração no material como um todo, pode-se dizer, com base nos dados obtidos para esta variável, que o primeiro estágio foi ineficiente na degradação do material. Enquanto que no primeiro estágio, que durou 60 dias, a redução do COT foi de $9,7 \%$, nos primeiros 30 dias do segundo estágio ela foi de $12 \%$. Kumar et al. (2007), analisando os experimentos, com base nas fontes de carbono palha de arroz e feno, verificou redução de 29,02 e $31,02 \%$, respectivamente. A diferença entre os valores deste trabalho e os obtidos pelos autores citados, pode ser devido ao conteúdo de água e da proporção de fonte de carbono de cada experimento. No presente trabalho foi adotada a relação de 0,2 $\mathrm{kg}$ de água e 0,26 kg de palha de café para cada $\mathrm{kg}$ de carcaças, enquanto nos experimentos de Kumar et al. (2007) essa relação foi de $1,7 \mathrm{~kg}$ de água e $1,75 \mathrm{~kg}$ de palha de arroz para $\mathrm{kg}$ de carcaça e 1,60 kg de água e $1,75 \mathrm{~kg}$ de feno para cada kg de carcaça. A adição de maior quantidade de água pode ser um fator importante para explicar o favorecimento da atividade microbiológica e, portanto a degradação do material, pois possibilitou a manutenção da umidade em níveis adequados, por maior período de tempo.

A relação $\mathrm{C} / \mathrm{N}$ inicial, calculada por balanço de massas, foi de 19:2, sendo as demais determinadas por amostragem. No primeiro estágio, as amostras foram coletadas na região das carcaças (na composteira). No segundo estágio, as amostras foram coletadas de maneira aleatória em toda a massa de compostagem.

$\mathrm{Na}$ Tabela 1 estão apresentados todos os valores da relação $\mathrm{C} / \mathrm{N}$ obtidos no primeiro e segundo estágios do processo.

Nos primeiros 20 dias do processo, houve degradação acelerada no entorno das carcaças, o que pode ser evidenciado pelos decréscimos acentuados nos valores de concentração de CFO e N (Tabela 1), o que pode ser debitado à presença de umidade e aeração adequadas no material. Depois disso, passou a ocorrer estabilização na concentração de CFO e grande perda de $\mathrm{N}$, provavelmente na forma de gás amônia, em decorrência das condições alcalinas do material. Com isso, a relação $\mathrm{C} / \mathrm{N}$ no material voltou a aumentar. Devido a questões de amostragem, associada à grande perda de $\mathrm{N}$ no processo, os valores da relação $\mathrm{C} / \mathrm{N}$, correspondente a 60 e 90 dias, respectivamente, foram superiores aos obtidos no balanço de massas inicial (Tabela 1).

As concentrações de sólidos voláteis (SV) estão apresentadas na Tabela 1 e variação ao longo do processo na Figura 4c. Esta variável é indicativa do teor de matéria orgânica nos materiais da mistura. A forma como ocorre a sua evolução ao longo do processo de compostagem permite inferir sobre o grau de estabilização do material, pois sua redução gradativa indica a transformação da matéria orgânica compostável em matéria mineralizada, conhecida como sólidos fixos e, principalmente, a transformação da matéria orgânica em dióxido de carbono e água. Os valores de SV estão 
diretamente ligados às variações nas concentrações de COT, portanto o comportamento esperado também seria de primeira ordem ou exponencial, porém isso não foi observado.

Comparando-se os valores de SV obtidos no 10 estágio com os calculados por balanço de massa observa-se que os primeiros estão maiores. Isso pode ser explicado pelo fato do valor inicial SV ter sido obtido em amostra retirada por ocasião da montagem da leira, mas não nas proporções em que se encontravam nela e, assim, havia maior quantidade de pedaços de frango na amostra. Como pode ser observado na Figura 4-C, nas quatro primeiras determinações, que correspondem aos 60 primeiros dias (10 estágio), praticamente não houve redução no valor de SV. Acredita-se que esses resultados sejam devidos ao fato da decomposição quase que exclusiva das carcaças de frango, nesse período. Como as carcaças corresponderam a cerca de $4 \%$ da massa total, conclui-se que apenas pequena parte do SV foi removido da mistura. Isso fica evidenciado quando se compara o valor de SV obtido ao final do 1을 estágio com os obtidos no 2을 estágio, ou seja, na etapa em que o composto foi revirado. Entre o primeiro valor de SV, que foi de $82.72 \mathrm{dag} \mathrm{kg}^{-1}$ e o quarto valor, obtido aos 60 dias, de 74,73 dag $\mathrm{kg}^{-1}$, a redução foi de $9,65 \%$. Na fase de reviramento, nos primeiros 30 dias, a redução foi $74,73 \mathrm{dag} \mathrm{kg}^{-1}$ para $65,46 \mathrm{dag} \mathrm{kg}^{-1}$, correspondendo a uma redução de $12,4 \%$ e a redução acumulada de SV foi de 22,06\%. AZEVEDO (1993), compostando a fração orgânica de Resíduos Sólidos Urbanos (RSU) pelo método das LEA, com aeração positiva, e pelo processo Windrow (reviramento), encontrou redução de SV da ordem de 36\%. A mesma autora, trabalhando com compostagem em LEA, sob sucção, encontrou redução média de $9 \%$.

A CTC mede a capacidade do composto de adsorver cátions. Sendo que essa capacidade será tanto maior, quanto maior for o índice de humificação do material. Isto porque as substâncias húmicas que compõe o composto são colóides eletronegativos com grande superfície específica. 0 processo de humificação, que ocorre, principalmente, na maturação e qualidade do composto, pode ser medida pelo valor da CTC do composto ou também pela relação CTC/COT, ou seja, estas variáveis dão indicativos do grau de maturação do composto orgânico. A variação dos valores obtidos para CTC e CTC/COT estão apresentados na Tabela 1.

Como pode ser observado a CTC, após 60 dias de manutenção na composteira, foi de $175 \mathrm{cmol}_{\mathrm{c}} \mathrm{kg}^{-1}$, o COT foi 41,52 dag kg-1 e a relação CTC/COT foi de 4,22. Após 90 dias de compostagem, 30 dias de reviramento no pátio de compostagem, o material retirado da composteira apresentou CTC de $209 \mathrm{cmol}_{\mathrm{c}} \mathrm{kg}^{-1}$, COT de $36,37 \mathrm{dag} \mathrm{kg}^{-1}$ e relação CTC/COT de 5,75 . Nos primeiros 30 dias de compostagem no 2 ㅇ Estágio, houve acréscimo de $19 \%$ no valor da CTC, juntamente com uma redução de 12,4 dag $\mathrm{kg}^{-1}$ na concentração de COT. Isto ocorreu devido à degradação da matéria orgânica, que proporcionou maior humificação do material, proporcionando aumento no valor da CTC e a transformação do COT em dióxido de carbono, reduzindo sua concentração. RODELLA \& ALCARDE, (1994) misturando serragem e turfa, em diferentes proporções, verificou que a CTC e a relação CTC/COT variava proporcionalmente ao teor de matéria orgânica presente na mistura. Nesse experimento, a CTC variou de $5.48 \mathrm{cmol}_{\mathrm{c}} \mathrm{kg}^{-1}$, na mistura com $0 \%$ de turfa, até $51,57 \mathrm{cmol}_{\mathrm{c}} \mathrm{kg}^{-1}$, na mistura com $41 \%$ de turfa. A relação CTC/COT variou de 0,35 a 3,38. Segundo HARADA \& INOKO (1980) valores de CTC/COT superiores a 1,7 indicam bom grau de humificação do material orgânico. De acordo com esse valor de referência, o material da composteira apresentou coeficiente de humificação de cerca de 2,5 vezes o valor de referência $(1,7)$, já no final do 1 o estágio de degradação, e de 3,5 vezes, nos 30 primeiros dias do 20 estágio.

Considerando que a destinação final de todo composto seja a sua aplicação no solo, para efeito de avaliação da eficiência de cada processo na eliminação de organismos patogênicos, foi usado, como referência, os valores contidos na resolução CONAMA 375 (BRASIL, 2006). Nesta resolução está estabelecido que, para haver aproveitamento agrícola do lodo de esgoto, no mesmo deve estar ausente a Salmonella em amostra de $10 \mathrm{~g}$ de ST e que a contagem de organismos de coliformes termotolerantes esteja menor que $10^{3} \mathrm{NMP} / \mathrm{g}$ de ST.

Os resultados das análises microbiológicas coliformes termotolerantes e a Salmonella estão mostrados na Tabela 2.

Tabela 2: Parâmetros microbiológicos analisado durante os processos de compostagem.

\begin{tabular}{|c|c|c|}
\hline Microrganismos & Dia & Resultado \\
\hline \multirow{4}{*}{ CTT a $45^{\circ} \mathrm{C}_{\left(\mathrm{NMP} \mathrm{g}^{-1}\right)}$} & 0 & $2.9 \times 10^{4}$ \\
& 20 & $<3$ \\
\cline { 2 - 3 } & 40 & $<3$ \\
\cline { 2 - 3 } & 60 & $<3$ \\
\cline { 2 - 3 } & 0 & Presença \\
\hline \multirow{3}{*}{ Salmonella $25 \mathrm{~g}$} & 20 & Ausência \\
\cline { 2 - 3 } & 40 & Ausência \\
\cline { 2 - 3 } & 60 & Ausência \\
\cline { 2 - 3 }
\end{tabular}


Os resultados apresentados na Tabela 2 comprovam a eficiência do primeiro estágio da composteira na eliminação de microrganismos indesejáveis. As temperaturas superiores a 65 ㅇ C no material mantidas no processo do 2 ㅇ ao 6 ㅇ dias (10 estágio) já foram suficientes para a eliminação ou inativação dos microrganismos monitorados. Os resultados apresentados indicam a eliminação e, ou, redução de Salmonella e coliformes termotolerantes, após 20 dias de execução da compostagem. Orrico Jr et al. (2010), em experimento semelhante, não obtiveram resultados satisfatórios, para CTT após o 10 estágio restando no material 9,3 $\times 10^{4} \mathrm{NMP} \mathrm{g}^{-1}$ de material. Os autores só alcançaram resultados satisfatórios após 100 dias de experimento, restando no material $230 \mathrm{NMP} \mathrm{g}^{-1}$ de material, sendo que os últimos 20 dias foram no segundo estágio, já na fase de reviramento. Acredita-se que a maior eficiência obtida neste trabalho se deva as altas temperaturas alcanças e mantidas durante o 10 estágio do processo.

\section{CONCLUSÃO}

Com base nos resultados conclui-se que:

- a palha de café proporcionou uma compostabilidade satisfatória, quando associados à cama de frango e carcaças de frango;

- as temperaturas atingidas, na primeira fase, foram suficientes para a eliminação das bactérias patogênicas e indicadores de interesse presentes no material;

- principalmente na primeira fase, o conteúdo de água no material foi fator limitante à degradação, o que se verificou pela baixa redução na concentração de sólidos voláteis;

No segundo estágio (reviramento ou Windrow) o coeficiente de humificação, denotado pela CTC ou CTC/COT, aumentou ainda mais.

- o sistema avaliado se mostrou eficiente na eliminação ou redução dos microrganismos Salmonella e coliformes termotolerantes, a níveis compatíveis com o que é exigido pela Resolução CONAMA № 375.

\section{REFERÊNCIAS BIBLIOGRÁFICAS}

AMERICAN PUBLIC HEALTH ASSOCIATION - Standard methods for the examination of water and wastewater. New York: APHA, WWA. WPCR, 19a. Ed., 1995.

ASSOCIAÇÃO DE AVICULTORES DA ZONA DA MATA AVIZOM. Relatório Técnico não publicado. Visconde do Rio Branco, Minas Gerais, 2006.

AZEVEDO, M.A. Estudo e avaliação de quatro modos de aeração para sistemas de compostagem em leiras. Belo Horizonte: Escola de Engenharia da UFMG.
(Dissertação de Mestrado) - Universidade Federal de Minas Gerais, 1993. 230p.

BRASIL, MINISTÉRIO DA AGRICULTURA PECUÁRIA E ABASTECIMENTO. Instrução Normativa №. 62/2003. Oficializa os Métodos Analíticos Oficiais para Análises Microbiológicas para Controle de Produtos de Origem Animal e Água. Brasília, 2003.

BRASIL, MINISTÉRIO DA AGRICULTURA PECUÁRIA E ABASTECIMENTO. Instrução Normativa №. 8/2004. Proíbe em todo território nacional a produção, comercialização e a utilização de produtos destinados à alimentação de ruminantes que contenham em sua alimentação proteínas e gordura de origem animal. Brasília, 2004.

BRASIL, MINISTÉRIO DO MEIO AMBIENTE. Resolução CONAMA №. 375/2006. Define critérios $e$ procedimentos para o uso agrícola de lodos de esgotos gerados em estações de tratamento de esgoto sanitário e seus produtos derivados, e dá outras providencias. Brasília, 2006.

COSTA, M.S.S.M.; COSTA, L.A.M.; PELÁ, C.J.S.; DECARLI, L.D.; MATTER, U.F. Desempenho de quatro sistemas para compostagem de carcaça de aves. Revista Brasileira de Engenharia Agrícola e Ambiental. Vol. 10, n. 3. Campina Grande - PB. 2006. p.692-698.

DAS, K.C.; MINKARA, M.Y.; MELEAR, N.D.; TOLLNER, E.W. Effect of poultry litter amendment on hatchery waste composting. J. Appl. Poult. Res., 11, 2002: p. 282- 290.

ENVIRONMENT PROTECION AGENCY (EPA). Review of On-Farm Disposal Treatment Risks and the Potential for Recycling of Wastesproduced from Commercial Chicken Farms and Processors. Australia, 1999.

GRAVES, R.E.; HATTEMER, G.M.; STETTLER, D.; KRIDER, J.N.; CHAPMAN, D. Composting. In: UNITED STATES DEPARTAMENT OF AGRICULTURE, NATURAL RESOURCES CONSERVATION SERVICE. Part 637 Environmental Engineering - National Engineering Handbook. Washington, 2000. 88p.

HARADA, Y.; YNOKO, A. Relationship between cationexchange capacity and the degree of maturity of city refuse composts. Soil Sci. Plant Nutr. 26, p.353-362. 1980.

HENRY, P.E.S.T. Capítulo 8, Dead Animal in: Poultry Training Manual. (2003) Disponivel em: http://www.clemson.edu/extension/livestock/livestock/ camm/poultry.html. Acesso em: 27/09/2011.

KENNER, H.M.; EWELL, D. L. Composting Livestock Mortalites, Road Kill, and Meat Processor By-Products in Ohio. NIAA Conference Paper. April, 9. Cincinnati, Ohio, 2003.

KIEHL, E.J. Fertilizantes Orgânicos. São Paulo, Editora Agronômica Ceres, 1985, 492p. 
KUBE, J. Carcass disposal by composting. Paper presented at the 35th Annual Convention of the American Association of Bovine Practitioners, Madison, Wisconsin. American Association of Bovine Practitioners 2002 Proceedings. p. 30-37.

KUMAR, V.R.S., SIVAKUMAR, K., PURUSHOTHAMAN, M.R., NATARAJAN, A.; AMANULLAH, M.M. Chemical Changes During Composting of Dead Birds With Caged Layer Manure. Journal of Applied Sciences Research, 3(10): 1100- 1104. INSInet Publication, 2007.

MATOS, A.T.; VIDIGAL, S.M.; SEDIYAMA, M.A.N.; GARCIA, N.C.P.; RIBEIRO, M.F. Compostagem de alguns resíduos orgânicos utilizando-se águas residuárias da suinocultura como fonte de nitrogênio. Revista Brasileira de Engenharia Agrícola e Ambiental, v.2, n.2, p. 199-203, 1998.

MATOS, A. T. Prática de tratamento e aproveitamento agrícola de resíduos sólidos. Associação de Engenheiros Agrícolas de Minas Gerais. Departamento de Engenharia Agrícola da UFV. (Série Caderno Didático no 45), Viçosa, 2006. 43p.

MUKHTAR, S.; KALBASI A.; AHMED A. Carcass Disposal: A Comprehensive Review. National Agricultural Biosecurity Center Consortium, USDA APHIS Cooperative Agreement Project, Carcass Disposal Working Group, Kansas State University. Kansas, 2004.

ORRICO JÚNIOR, M.A.P.; ORRICO, A.C.A.; LUCAS JÚNIOR, J. Compostagem dos resíduos da produção agrícola: cama de frangos e carcaças de aves. Engenharia Agrícola, Jaboticabal, v.30, n.3, p.538-545, 2010.

PEDROSO-DE-PAIVA, D. Guia para operar uma compostagem de aves mortas - tradução: Fonte: Circular ANR-580, Alabama Cooperative Extension Service, Auburn University, Alabama - USA, EMBRAPA, 2004.

RODELLA, A.A.; ALCARDE, J.C. Avaliação de materiais orgânicos empregados como fertilizantes. Sci. Agrícola, Piracicaba, 51(3):556-562, set./nov. 1994.

UNITED STATES ENVIRONMENTAL PROTECTION AGENCY (USEPA). Disposal of Domestic Birds Infected by Avian Influenza - An Overview of Considerations and Options. EPA530-R-06-009, 2006. 